\section{Case Reports in Ophthalmology}

\title{
Correction of High Astigmatism after Penetrating Keratoplasty with Toric Multifocal Intraocular Lens Implantation
}

\author{
Raffaele Nuzzi Francesca Monteu \\ M.D. Eye Clinic Section, University of Turin, Ophthalmic Hospital, Turin, Italy
}

\section{Keywords}

Corneal herpetic leukoma $\cdot$ High astigmatism $\cdot$ Penetrating keratoplasty $\cdot$ Toric multifocal intraocular lens

\begin{abstract}
After penetrating keratoplasty (PK), high astigmatism is often induced, being frequently about 4-6 dpt. According to the entity and typology of astigmatism, different methods of correction can be used. Selective suture removal, relaxing incisions, wedge resections, compression sutures, photorefractive keratectomy, and laser-assisted in situ keratomileusis can reduce corneal astigmatism and ametropia, but meanwhile they can cause a reduction in the corneal integrity and cause an over- or undercorrection. In case of moderate-to-high regular astigmatisms, the authors propose a toric multifocal intraocular lens (IOL) implantation to preserve the corneal integrity (especially in PK after herpetic corneal leukoma keratitis). We evaluated a 45-year-old patient who at the age of 30 was subjected to PK in his left eye due to corneal leukoma herpetic keratitis, which led to high astigmatism (7.50 dpt cyl. $\left.5^{\circ}\right)$. The patient was subjected to phacoemulsification and customized toric multifocal IOL implantation in his left eye. The correction of PK-induced residual astigmatism with a toric IOL implantation is an excellent choice but has to be evaluated in relation to patient age, corneal integrity, longevity graft, and surgical risk. It seems to be a well-tolerated therapeutic choice and with good results.




\section{Case Report}

After penetrating keratoplasty (PK), high astigmatism is often induced, being frequently about 4-6 dpt. According to the entity and typology of astigmatism, different methods of correction can be used. In case of moderate-to-high regular astigmatisms, a toric multifocal intraocular lens (IOL) implantation is proposed.

We evaluated a 45-year-old patient who at the age of 30 was subjected to PK in his left eye due to corneal leukoma herpetic keratitis, with moderate cortical lens opacities. This led to high astigmatism $\left(7.50 \mathrm{dpt}\right.$ cyl. $\left.5^{\circ}\right)$. The uncorrected distance visual acuity of his right eye was $10 / 10$ and the uncorrected distance visual acuity of his left eye was $1 / 50$; the bestcorrected distance visual acuity of his left eye was 2/10.

The patient was subjected to phacoemulsification and customized toric multifocal IOL implantation in his left eye (SOLEKO ${ }^{\mathrm{TM}}$ TORIC IOL FIL611PVT 6.25 SF, 9 cyl. $6^{\circ}$ ). Thirty days after the surgery, the visual acuity of his left eye was $6 / 10$ without correction. The spheroequivalent was within $\pm 0.50 \mathrm{dpt}$ of the intended value and the refractive astigmatism was less than $1.00 \mathrm{dpt}$.

The corneal graft was transparent, the endothelial cell loss was not significant, the toric IOL provided good postoperative rotation stability, and the orthoptic control did not find ocular dominance variations, with a good stereopsis and binocular vision.

\section{Discussion}

As demonstrated in the literature, after PK, residual astigmatism is common, which can vary between 4 and $6 \mathrm{dpt}$. Better results in the astigmatism reduction at the first-year control were only found in pediatric patients [1].

To correct PK-induced residual astigmatism, and therefore the limitation to the visual function and the reduction in the patients' satisfaction, several methods were employed.

In cases of low-to-moderate astigmatism, spectacles can be used or contact lenses in cases of anisometropia. Both solutions may sometimes not be well tolerated by the patients. Moreover, the spectacles can cause aberrations, sometimes the astigmatism is irregular, and the contact lenses might not be suitable for transplanted corneas. According to the literature, the proportion of eyes that cannot be corrected without surgery lies between 8 and 20\% [2]. For this reason, $8 \%$ of the patients who underwent surgical transplant of the cornea had to be treated with refractive surgery [2]. In these cases, corneal incisions, photorefractive keratectomy, and laser-assisted in situ keratomileusis were proposed [3].

Considering that with aging these patients will develop cataract and that the cataract surgery techniques are improving, both PK-induced astigmatism and cataract can be treated with phacoemulsification and implantation of a toric IOL.

Many small studies about implantation of toric IOLs can be found in the literature with excellent results, as observed by Stewart and McAlister [4], Srinivasan et al. [5], Wade et al. [6], and Muftuoglu et al. [7]. Overall, the endothelial cell loss is between 5 and $10 \%$ and the IOL stability is excellent $[2,8]$.

Excellent results can be obtained by secondary sulcus implantation of piggyback toric IOLs in pseudophakic eyes [5, 9]. Meyer and McGhee [9] demonstrated an uncorrected distance visual acuity changing from 1.2 to 0.3 after a year of follow-up. Thomas et al. [10] demonstrated an astigmatism reduction of $70.95 \%$. 
Selective suture removal, relaxing incisions, wedge resections, compression sutures, photorefractive keratectomy, and laser-assisted in situ keratomileusis can reduce corneal astigmatism and ametropia, but meanwhile they can cause a reduction in the corneal integrity and cause an over- or undercorrection; instead, toric IOLs preserve the corneal integrity, especially in PK after herpetic corneal leukoma keratitis.

PK-induced residual astigmatism is often irregular; thus, this typology cannot be corrected by toric IOLs. Karabatsas et al. [11] found 72\% of irregular astigmatism 12 months after surgery; therefore, the better results after toric IOL implantation will be in cases of preponderantly regular astigmatism.

Another factor to be considered is the high risk of herpetic pathology recurrence in specific patients after corneal surgery. The authors decided not to use acyclovir as a prophylaxis, but to use a high-molecular-weight viscoelastic substance, such as Viscoat (Alcon). Twelve months after surgery, the endothelial count was unchanged and no herpetic recurrences or endothelial decompensation occurred.

In conclusion, the correction of PK-induced residual astigmatism with toric IOL implantation is an excellent choice but has to be evaluated in relation to patient age, corneal integrity, longevity graft, and surgical risk. It seems to be a well-tolerated therapeutic choice and with good results.

\section{Statement of Ethics}

This study followed the tenets of the Declaration of Helsinki. Personal identifiers were removed because consent to publishing such information was not obtained.

\section{Disclosure Statement}

The authors have no conflicts of interest to disclose. This is an unfunded study.

\section{References}

1 Vail A, Gore SM, Bradley BA, Easty DL, Rogers CA, Armitage WJ: Conclusions of the corneal transplant follow up study. Collaborating surgeons. Br J Ophthalmol 1997;81:631-636.

-2 Lockington D, Wang EF, Patel DV, Moore SP, McGhee CN: Effectiveness of cataract phacoemulsification with toric intraocular lenses in addressing astigmatism after keratoplasty. J Cataract Refract Surg 2014;40:2044-2049.

-3 Webber SK, Lawless MA, Sutton GL, Rogers CM: LASIK for post penetrating keratoplasty astigmatism and myopia. Br J Ophthalmol 1999;83:1013-1018.

4 Stewart CM, McAlister JC: Comparison of grafted and non-grafted patients with corneal astigmatism undergoing cataract extraction with a toric intraocular lens implant. Clin Exp Ophthalmol 2010;38:747-757.

-5 Srinivasan S, Ting DS, Lyall DA: Implantation of a customized toric intraocular lens for correction of postkeratoplasty astigmatism. Eye (Lond) 2013;27:531-537.

-6 Wade M, Steinert RF, Garg S, Farid M, Gaster R: Results of toric intraocular lenses for post-penetrating keratoplasty astigmatism. Ophthalmology 2014;121:771-777.

7 Muftuoglu IK, Akova YA, Egrilmez S, Yilmaz SG: The results of toric intraocular lens implantation in patients with cataract and high astigmatism after penetrating keratoplasty. Eye Contact Lens 2016;42:e8-e11.

-8 De Sanctis U, Eandi C, Grignolo F: Phacoemulsification and customized toric intraocular lens implantation in eyes with cataract and high astigmatism after penetrating keratoplasty. J Cataract Refract Surg 2011;37:781-785. 
Nuzzi and Monteu: Correction of High Astigmatism after Penetrating Keratoplasty with Toric Multifocal Intraocular Lens Implantation

99 Meyer JJ, McGhee CN: Supplementary, sulcus fixated intraocular lens in treatment of spherical and astigmatic refractive errors in pseudophakic eyes after keratoplasty. Cornea 2015;34:1052-1056.

10 Thomas BC, Auffarth GU, Reiter J, Holzer MP, Rabsilber TM: Implantation of three-piece silicone toric additive IOLs in challenging clinical cases with high astigmatism. J Refract Surg 2013;29:187-193. Karabatsas CH, Cook SD, Sparrow JM: Proposed classification for topographic patterns seen after penetrating keratoplasty. Br J Ophthalmol 1999;83:403-409. 